\title{
PRÁTICAS PEDAGÓGICAS E EDUCAÇÃO DO CAMPO: PAULO FREIRE
}

\author{
Ellen Simone Alves de Souza ${ }^{1}$ \\ Geicele Gomes Barbosa ${ }^{2}$ \\ Michelli Carla de Souza ${ }^{3}$ \\ Sinara Martins dos Santos ${ }^{4}$
}

RESUMO: A presente pesquisa tem como objetivo abordar a educação do campo sob a perspectiva do autor Paulo Freire. Busca-se caminhos alternativos por meio dos postulados do referido autor, rumo a melhorias que tornem o ensino $e$ a aprendizagem mais eficientes e adequados à contemporaneidade singular e híbrida, onde os extremos de acesso às oportunidades são mais evidenciados e quase intransponíveis. Nesse pensamento faremos análise terá como ponto de partida a obra Pedagogia da Autonomia de Paulo Freire, à qual traz-nos propostas de práticas pedagógicas necessárias à educação, especialmente àquela voltada às classes populares. Assim, buscamos analisar em que medida a pedagogia proposta por Paulo Freire pode ser visualizada como uma construção capaz de contribuir com a consolidação de uma pedagogia para a educação das classes populares e que pretende se afirmar como espaço/tempo privilegiado, articulados por diversos contextos subjetivos, sociais e culturais, onde os educandos poderão ser assumidos como sujeitos críticos e criativos.

Palavras chave: Paulo Freire. Educação do campo. Educação popular.

ABSTRACT: This research aims to approach rural education from the perspective of author Paulo Freire. Alternative paths are sought through the aforementioned author's postulates, towards improvements that make teaching and learning more efficient and adequate to the unique and hybrid contemporaneity, where the extremes of access to opportunities are more evident and almost insurmountable. In this thinking, we will analyze the work Pedagogy of Autonomy by Paulo Freire as a starting point, which brings us proposals for pedagogical practices necessary for education, especially those aimed at the popular classes. Thus, we seek to analyze to what extent the pedagogy proposed by Paulo Freire can be seen as a construction capable of contributing to the consolidation of a pedagogy for the education of the popula classes and that intends to assert itself as a privileged space/time, articulated by different subjective contexts, social and cultural, where students can be assumed as critical and creative subjects.

Keywords: Paulo Freire. Rural education. Popular education.

\footnotetext{
rellendirceu@outlook.com

22 geicelegobarbosa@gmail.com

${ }^{3}$ Pedagoga com pós- graduação em Psicopedagogia institucional. Professora atuante em escola pública.

${ }^{4}$ sinara2021@gmail.com
} 


\section{INTRODUÇÃO}

Podemos ressaltar com a pesquisa de estudo que o referido conceito de educação do campo foi formulado a partir da iniciativa de movimentos populares do campo, que começaram a pressionar o Estado por políticas públicas específicas para as populações não-urbanas. Até então as escolas rurais eram sucateadas e eram desassistidas pelo poder público, logo ainda nos tempos de hoje tem muitas pessoas em idade escolar vivendo no campo.

Dessa forma, torna-se necessário pesquisar como essas desigualdades marcam profundamente a construção ou a não-construção do sistema educativo, de políticas educativas, de garantias de direitos, especificamente do direito à educação. (ARROYO, 2006, p.104). Entendendo que o fracasso educacional está diretamente relacionado a sistema educacional pouco eficaz, onde não há observância de postulados básicos da pedagogia humanista, além de desprezarem conexões entre o ensino e o contexto socioeconômico e cultural dos educandos.

Visto que se busca caminhos alternativos, através deste autor, rumo a melhorias que tornem o ensino e a aprendizagem mais eficientes e adequados à contemporaneidade singular e híbrida, onde os extremos de acesso às oportunidades são mais evidenciados e quase intransponíveis. Aprender significativamente nas práticas freirianas - base humanista - não ocorre apenas num aspecto cognitivo, e sim, na relação com o mundo vivido.

Neste sentido, entende-se a necessidade de se fazer uma análise do perfil acadêmico desses profissionais, formá-los continuamente e motivá-los com vistas à construção de uma educação verdadeiramente transformadora.

Dessa forma, nossa análise terá como ponto de partida a obra Pedagogia da Autonomia do professor Paulo Freire, à qual traz-nos propostas de práticas pedagógicas necessárias à educação, a fim de refletir acerca de conceitos de capacitação, ética e práticas pedagógicas adequadas.

Nesta linhagem buscaremos caminhos alternativos, através deste autor, rumo a melhorias que tornem o ensino e a aprendizagem mais eficientes e adequados à contemporaneidade singular e híbrida, onde os extremos de acesso às oportunidades são mais evidenciados e quase intransponíveis, aprender 
significativamente nas práticas freirianas - base humanista - não ocorre apenas num aspecto cognitivo, e sim, na relação com o mundo vivido.

Logo que sua prática educativa vai muito além do âmbito escolar, se desenvolve também nos espaços sociais, visto que para ele o processo educativo é visto como um ato político, entende-se a necessidade de se fazer uma análise do perfil acadêmico desses profissionais, formá-los continuamente e motivá-los com vistas à construção de uma educação verdadeiramente transformadora. Dessa forma, nossa análise terá como ponto de partida a obra Pedagogia da Autonomia do professor Paulo Freire, à qual traz-nos propostas de práticas pedagógicas necessárias à educação.

O pensador e educador brasileiro Paulo Freire foi um dos maiores estudiosos que possibilitou, através de seus estudos e pesquisas, uma visão de educação popular alternativa, que viabilizasse uma formação que tivesse sentido para os educandos. Com proposta político-pedagógica de Paulo Freire, desde os seus primeiros escritos em meados da década de 40, defendia uma educação que levasse em consideração o respeito ao saber das classes populares, como prática educativa, numa relação dialógica democrática. Para esse educador, a leitura de mundo dos educandos - seus conhecimentos adquiridos ao longo da vida - é o ponto de partida no processo de ensino-aprendizagem.

No entendimento de Freire (2003, p.85): Somente uma escola centrada democraticamente no seu educando e na sua comunidade local, vivendo as suas circunstâncias, integrada com seus problemas, levará os seus estudantes a uma nova postura diante dos problemas de contexto".

Visto que, Freire nos propõe um modelo de educação que leve o sujeito a sair do conformismo e do comodismo que lhe é imposto pela escola através de conteúdos repetitivos e descontextualizados da realidade dos educandos. Onde sua proposta revolucionou a educação nos anos 6o, por defender a ideia de que a alfabetização deve ser feita através da realidade vivida pelo aprendiz, porquanto é respeitando o repertório do educando que se pode chegar a uma visão de mundo crítica e transformadora da realidade. 
Para Freire (2007, p.102): Não seria, porém, com essa educação desvinculada da vida, centrada na palavra, em que é altamente rica, mas na palavra "milagrosamente" esvaziada da realidade que deveria representar, pobre de atividades com que o educando ganhe a experiência do fazer, que desenvolveríamos no brasileiro a criticidade de sua consciência, indispensável à nossa democratização.

Nesse processo de alfabetização, Freire busca transformar a consciência ingênua do alfabetizando em consciência crítica, com o compromisso de formá-lo para usar a escrita e a leitura como instrumento social, posto que concebê-la é sobremaneira importante se entender que "o comando da leitura e da escrita se dá a partir de palavras e temas significativos à experiência comum dos alfabetizando, e não de palavra e de temas apenas ligados à experiência do educador” $(2009$, p.)

Em referência com Paulo Freire e Pedagogia do Campo Ensinar exige que compreendamos que a educação é uma forma de intervenção no mundo, isto é, a Educação é uma forma de transformação da realidade, politicamente dada e socialmente condicionada, que, portanto, não há como ser considerada com indiferença ou desprezo, uma vez que todo pensamento é dado por um viés ideológico. Cabe ao educador esclarecer, conscientizar, problematizar e oferecer as ferramentas da própria emancipação aos educandos, seja no âmbito intelectual, social, moral e ético.

Cada profissional da educação deverá estar capacitado para exercer o cargo de educador do futuro, propiciar condições aos educandos, em suas socializações com os outros e com o professor, de testar a experiência, de assumir-se como um ser histórico e social, que pensa, que critica, que opina, que tem sonhos, sujeito consciente e potencial agente transformador de sua própria história.

E assim o Paulo Freire enfatizou sempre em suas obras e falas que sua proposta teórica pedagógica não se restringe a repetir palavras sem seu real significado, mas colocar o educando em condições de pensar, propor e agir criticamente em seu mundo, é imprescindível que o educador conheça a realidade social dos sujeitos educandos, para, posteriormente, desenvolver práticas pedagógicas que tenham significado para eles.

O educando das classes populares, como refere Freire, está inserido em uma realidade social política econômica e cultural, que deve ser valorizada pelo educador 
na organização do material pedagógico. De acordo com dados do Censo Escolar 2oII, de um total 76,2 mil escolas rurais, 42 mil são multisseriadas, quase $15 \%$ ainda não possuem energia elétrica, 89\% não têm biblioteca e 81\% não contam com laboratório de informática.

Com uma realidade de infraestrutura precária, um levantamento do Fundo das Nações Unidas para a Infância (Unicef) feito com base na Pesquisa Nacional por Amostra de Domicílios (Pnad) de 2009 indica que 2,5\% das crianças e dos adolescentes com idade entre 7 e 14 anos que vivem no campo estão fora da escola, e aos dados apresentados pelo Censo Escolar podemos entrever que a realidade da educação no campo é bem diferente, se comparada à educação urbana.

A escola do campo é assim definida por receber quilombolas, índios, pescadores, extrativistas, agrícolas, assentados, dentre outros, e não por localização espacial. Onde a educação do campo é vista por muitos como uma educação desnecessária, já que os trabalhadores usam mão-de-obra braçal para o desempenho de suas atividades, sendo desnecessária, na visão de muitos, a utilização de recursos educacionais específicos disponibilizados nas escolas urbanas.

E, esse descaso, segundo pesquisa realizada por Caldart (2004, p.149), está atrelado ao encurtamento dos horizontes políticos e educacionais para os povos do campo, o qual reflete a visão pessimista do campo e da educação do campo pautada na crença de que "para mexer com a enxada ou cuidar do gado não são necessários nem letras nem competências.

E quanto um educador é preciso considerar o saber de "experiência feito" pelos grupos populares, sua explicação do mundo e a compreensão de sua própria presença nele, logo, pode-se dialogar com eles, desafiando-os a pensar sua história social e a perceber a necessidade de superarem certos saberes que se revelam inconsistentes para explicar os fatos. Já o fundamental que o educador, conforme elucida Freire, respeite a "leitura do mundo" do educando, sua bagagem cultural que, também, é fruto de seu contexto geopolítico e cultural.

Visto que, este novo conhecimento a ser apreendido pelos educandos das classes populares, tem que incorporar a leitura de mundo, seus interesses, necessidades, anseios, sonhos; mas depreende-se, portanto, a indagação: profissionais 
que não estão inseridos na lógica do campo e não tiveram uma formação voltada para esta comunidade, estão preparados para esta nova ética emancipadora de conhecimento desses sujeitos? E a participação deles no processo de ensino como sujeitos ativos, com uma postura crítica sobre a realidade, é fundamental e tudo deve ser considerado e aproveitado em todas as etapas da aprendizagem.

No entanto a identidade da escola do campo é definida pela sua vinculação às questões inerentes a sua realidade, ancorando-se na temporalidade e saberes próprios dos estudantes, na memória coletiva que sinaliza futuros, na rede de ciência e tecnologia disponível na sociedade e nos movimentos sociais em defesa de projetos que associem as soluções exigidas por essas questões à qualidade social da vida coletiva no país.

No entanto, os profissionais da educação do campo não têm preparo específico para este tipo de docência, pois geralmente a maioria dos profissionais que são designados para ministrar aulas no campo, são provenientes do meio urbano, e não possuem conhecimento acerca dessa realidade, outros profissionais sequer possuem ensino superior, conforme dados do INEP apresentados anteriormente.

Onde é retratado no $5^{\circ}$ Parágrafo assinala que: As propostas pedagógicas das escolas do campo, respeitadas as diferenças e o direito igualdade e cumprindo imediata e plenamente o estabelecido nos arts. 23, 26 e 28 da Lei 9.394/96, contemplarão a diversidade do campo em todos os seus aspectos: sociais, culturais, políticos, econômicos, de gênero, geração e etnia.

E referente aos educadores do campo precisam de formação superior direcionada e comprometida com uma educação libertadora, crítica e consciente que possa contribuir diretamente na formação de educandos ativos e conscientes da realidade que o cerca, para que dessa forma possa intervir e transformar o meio em que vive.

Logo, partindo desse pressuposto o Projeto Político Pedagógico deve levar em consideração: as vivências, as especificidades, as experiências políticas dos sujeitos, de modo a incentivar a permanência dos mesmos no campo.

E assim, dessa forma, mediante o quadro desenhado para a educação no campo, Paulo Freire, em Pedagogia da Autonomia (1996), deixa claro em seus 
postulados que antes de tudo, a educação é um ato inteiramente político, e dentro dessa perspectiva não se pode deixar de levar em consideração a ética nas relações humanas, através do diálogo e com respeito à diferença de ideias e posições, já que o ato de ensinar exige a corporificação das palavras pelo exemplo.

Já, no caso o ensino não esteja em sintonia com o conhecimento de mundo do educando, o conhecimento poderá ser acumulado como se fosse uma aplicação bancária e não promove as mudanças que se esperavam de quem o recebe.

\section{CONSIDERAÇÕES}

Podemos que, aos estes enunciados: "conteúdos que são desconectados da realidade", "educação verticalizada do homem sobre o homem", "memorização mecânica dos conteúdos”, etc. Sendo um modelo de educação bancária exclusivamente mecânica perpetuadora do status quo, onde os educandos são obrigados a memorizar os conteúdos e a aprender de forma arbitrária e literal, ou seja, uma aprendizagem sem compreensão, sem significado - tem de ser superado. E para tal faz -se crucial a concepção de processo educativo que esteja voltado para a libertação de forma significativa, onde os educandos façam parte desse processo educativo como seres ativos, agentes conscientes, motivadores e transformadores sociais. Onde a prática educativa é um constante exercício em favor da construção e do desenvolvimento da autonomia de professores e alunos, não obstante transmitindo saberes, mas dando significados, construindo e redescobrindo os mesmos, para aprender e por consequência para ensinar, intervir, conhecer, sonhar, transformar. Elencamos aqui algumas inquietações, provocações e possíveis caminhos pedagógicos para conquistar maior êxito e eficácia no processo educacional. Logo temos consciência de que recorte de ideias aqui apresentado não é suficiente para abarcar o horizonte de possibilidades de contribuição de Paulo Freire para uma pedagogia da educação popular emancipadora e crítica, por fim, que a máxima de Paulo Freire faça sentido e que vejamos mais exemplos no processo ensino-aprendizagem norteados pela crença de que "exercitaremos tanto mais e melhor a nossa capacidade de aprender e de ensinar quanto mais sujeitos, e não puros objetos, do processo nos façamos" (p.65). E assim desejamos que através destes e 
outros saberes, educandos, educadoras e educadores possam vivenciar juntos a construção de saberes libertadores e significativos. No mais promover uma educação libertadora e humanista faz-se dever de todo e qualquer educador comprometido com valores de ética, solidariedade e criticidade, e só denunciando uma realidade vivida que se é possível projetar outra realidade desejável, e retratando em educação podemos ressaltar que a educação popular tem matrizes que estão muito presentes na educação do campo e por isso pode ser afirmar que é uma relação consolidada, tanto na prática como na teoria, a relação entre ambas é marcada, sobretudo pela luta dos movimentos populares que buscam transformar a realidade social por meio da educação. Onde a educação do campo é uma proposta abrangente que visa à formação do homem do campo e também a valorização no que diz respeito ao espaço, tempo e modelo de currículo, que mobilize as atividades campesinas abrangentes a toda a família, bem como as estratégias para o desenvolvimento sustentável. Visto que a escola do campo é assim definida por receber quilombolas, índios, pescadores, extrativistas, agrícolas, assentados, dentre outros, e não por localização espacial. Em que constatamos que Freire, talvez por sua teoria da educação se constituir em uma pedagogia humanista e libertadora, faz fortes críticas à aprendizagem mecânica ou memorística, como mostram estes enunciados: "conteúdos que são desconectados da realidade", "educação verticalizada do homem sobre o homem”, "memorização mecânica dos conteúdos”, etc. Sendo um modelo de educação bancária exclusivamente mecânica perpetuadora do status quo, onde os educandos são obrigados a memorizar os conteúdos e a aprender de forma arbitrária e literal, ou seja, uma aprendizagem sem compreensão, sem significado - tem de ser superado, onde os educandos façam parte desse processo educativo como seres ativos, agentes conscientes, motivadores e transformadores sociais. Prática educativa é um constante exercício em favor da construção e do desenvolvimento da autonomia de professores e alunos, não obstante transmitindo saberes, mas dando significados, construindo e redescobrindo os mesmos, para aprender e por consequência para ensinar, intervir , conhecer, sonhar, transformar, para uma pedagogia da educação popular emancipadora e crítica. Intenta-se, por fim, que a máxima de Paulo Freire faça sentido e que vejamos mais exemplos no processo ensino-aprendizagem norteados 
pela crença de que "exercitaremos tanto mais e melhor, e assim promover uma educação libertadora e humanista faz-se dever de todo e qualquer educador comprometido com valores de ética, onde as crianças são umas das possiblidades de um futuro melhor, e que o hoje é a semente da árvore de amanhã.

\section{REFERÊNCIAS}

- Paulo Freire e o projeto popular para o Brasil. In. CALDART, R. S.; KOLLING, E. G. PAULO FREIRE: um educador do povo. 2. ed. Veranópolis, RS: PERES, 200Ib. p. 54-62.

ARROYO, Miguel; CALDART, Roseli; MOLINA, Mônica (orgs). Por uma educação do campo. Petrópolis, RJ: Vozes, 2004. A escola do campo e a pesquisa do campo: metas. In:

BRANDÃO, C. A educação popular na escola cidadã. Petrópolis: Vozes, 2002.

BRASIL. Ministério da Educação. Conselho Nacional de Educação. Parecer CNE/CEB № 36/200I.

Diretrizes Operacionais para a Educação Básica nas Escolas do Campo. Brasília: MEC/CNE, 2002. BRASIL. Ministério da Educação. Lei no 9.394, de 20 de dezembro de 1996.Estabelece as Diretrizes e Bases da Educação Nacional. Brasília, Diário Oficial da União, 20-12-1996.

FREIRE, P. Pedagogia da autonomia: saberes necessários à prática educativa. 34. ed. São Paulo: Paz e Terra, 2006.

COUTINHO, Carlos Nelson. Marxismo e política: a dualidade de poderes e outros ensaios - 2. Ed. - São Paulo: Cortez, 1996.

FREIRE, P. Pedagogia do oprimido. São Paulo: Paz e Terra, 2005. (200I)

Pedagogia da Esperança (8ª edição). São Paulo: Paz e Terra.

Freire. P. A importância do ato de ler: em três artigos que se completam. 5o. ed. São Paulo: Cortez. 2009.

MOLINA, Mônica C. Educação do campo e pesquisa: questões para reflexão. Brasília: Ministério do Desenvolvimento Agrário, 2006,pıо3-ı16 .

LEITE, S. C. Escola rural: urbanização e políticas educacionais. São Paulo: Cortez, 1999. 